\title{
Preservation of residual hearing after cochlear implant surgery with slim modiolar electrode
}

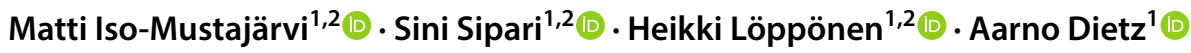

Received: 30 June 2019 / Accepted: 22 October 2019 / Published online: 31 October 2019

(c) The Author(s) 2019

\begin{abstract}
Purpose To evaluate the insertion results and hearing preservation of a novel slim modiolar electrode (SME) in patients with residual hearing.

Methods We retrospectively collected the data from the medical files of 17 patients (18 ears) implanted with a SME. All patients had functional low frequency hearing $\left(\mathrm{PTA}_{(0.125-0.5 \mathrm{kHz})} \leq 80 \mathrm{~dB} \mathrm{HL}\right)$. The insertion results were re-examined from the postoperative cone-beam computed tomography scans. Postoperative thresholds were obtained at the time of switch-on of the sound processors (mean 43 days) and at latest follow-up (mean 582 days). The speech recognition in noise was measured with the Finnish matrix sentence test preoperatively and at follow-up.

Results The mean insertion depth angle (IDA) was $395^{\circ}$. Neither scala dislocations nor tip fold over were detected. There were no total hearing losses. Functional low-frequency hearing was preserved in 15/18 (83\%) ears at switch-on and in 14/17 (82\%) ears at follow-up. According to HEARRING classification, 55\% (10/18) had complete HP at switch-on and 41\% (7/17) still at follow-up. Thirteen patients (14 ears) were initially fitted with electric-acoustic stimulation and seven patients $(8$ ears) continued to use it after follow-up.

Conclusions The preliminary hearing preservation results with the SME were more favorable than reported for other perimodiolar electrodes. The results show that the array may also be feasible for electro-acoustic stimulation; it is beneficial in that it provides adequate cochlear coverage for pure electrical stimulation in the event of postoperative or progressive hearing loss.
\end{abstract}

Keywords Cochlear implant $\cdot$ Hearing preservation $\cdot$ Modiolar electrode $\cdot$ Electro-acoustic stimulation

\section{Introduction}

The preservation of the delicate inner ear structures has become a major consideration in cochlear implant surgery as intracochlear trauma has been shown to negatively affect the post-implant hearing results [1-5]. Due to the more advanced surgical techniques and more delicate electrode arrays, post-operative results have improved during recent years. This has led to an expansion of the use of these devices, now including also patients with functional residual hearing. Patients with substantial residual hearing in the lower frequencies may benefit from cochlear implantation by

Matti Iso-Mustajärvi

matti.iso-mustajarvi@kuh.fi

1 University of Eastern Finland, Yliopistonranta 1, 70210 Kuopio, Finland

2 Kuopio University Hospital, Ear, Nose and Throat Diseases, KNK-klinikka, Puijonlaaksontie 2, 70210 Kuopio, Finland combined electric-acoustic stimulation (EAS), provided that their hearing can be preserved at surgery. First described by von Ilberg et al. [6], the physiological acoustic stimulation in the low frequencies combined with the electric stimulation by the cochlear implant has been shown to enhance the postoperative hearing results in terms of better sound quality, improved music listening abilities and better speech recognition against background noise [7-11] Although residual hearing can be preserved with longer lateral wall electrodes (LWE), much more favorable results have been reported for shorter LWE. For short electrodes ( $\leq 20 \mathrm{~mm}$ active length), the hearing preservation rates vary from 54 to $88 \%$, depending on the classification [10-14]. The disadvantage of short arrays is that in the event of a total postoperative hearing loss, the incomplete cochlear coverage may compromise the outcome with pure electrical stimulation. For electric hearing, deeper insertion angles have been shown to provide significantly better speech perception results $[4,15,16]$. The hearing preservation results for these standard length LWEs 
(i.e. $>20 \mathrm{~mm}$ active length) vary from 11.3 to $77.7 \%$ [14, 17-20].

Conventional (i.e. stylet type) perimodiolar electrodes (PME) are reported to cause more trauma as compared to lateral wall electrodes (LWE) [16, 21, 22, 23]. Thus, the use of PMEs for hearing preservation surgery is seldom justified. Due to the closer proximity to the modiolus and the spiral neurons, PMEs may provide electro-physiological advantages, such as lower current consumptions and possibly more localized stimulation. However, there are no convincing data that these potential benefits are related to better clinical outcomes [3, 24-26].

A new PME, the slim modiolar electrode (SME) (Cochlear Company, Sydney, Australia) was recently designed for atraumatic insertion. The aim of this study was to analyze the clinical insertion and hearing preservation results of the SME.

\section{Materials and methods}

We retrospectively collected the data from the medical files of 17 patients (18 ears) implanted with the SME. Patients with relevant functional hearing, defined as preoperative low-frequency PTA $(0.125-0.5 \mathrm{kHz}) \leq 80 \mathrm{~dB}$ (HL) were included in this study [27]. Patients with vestibulo-cochlear anomalies or cochlear fibrosis and/or ossification were excluded. The study had institutional approval (No. 5551850). Preoperative hearing thresholds were available from all patients and results from the Finnish Matrix Sentence Test (FMST) in 16 patients. Speech recognition was measured with the novel FMST, the standard speech-in-noise test was used in adult CI recipients to measure hearing performance [28, 29]. Randomized 20 -sentence test lists and a non-fluctuating speechspectrum shaped noise at a constant level of $65 \mathrm{~dB}$ SPL were used as speech and noise signals. The speech reception threshold (SRT), i.e. the signal-to-noise ratio at which 50\% of the test items are correctly recognized, was determined in an adaptive test measurement procedure. One child was an immigrant with insufficient language skills and the other child had mild autism spectrum disorder (cases 4 and 7) and could not perform the FMST. All measurements were performed in the best-aided condition.

All patients underwent routine pre-operative magnetic resonance imaging (MRI) and high-resolution computed tomography (HRCT) to rule out cochlear malformation or retrocochlear pathology. All patients had normal temporal bone and labyrinthine anatomy.

The SME is a new generation PME, whose volume is approximately $40 \%$ smaller than the Contour array. The internal stylet was replaced by an external sheath to keep the electrode straight prior to its insertion. The SME has a diameter of $0.35 \times 0.4 \mathrm{~mm}$ at the tip and $0.45 \mathrm{~mm} \times 0.5 \mathrm{~mm}$ at the base.

All patients underwent cochlear implantation via a transmastoid posterior tympanotomy approach under general anesthesia according to the institution's hearing preservation protocol. The patients were given cefuroxime $1.5 \mathrm{~g}$ and dexamethasone 7.5-10 mg intravenously during induction. Weight equivalent doses were administered to the pediatric patients. The bony overhang over the round window (RW) was carefully drilled down to largely expose the round window membrane (RWM). A Spongostan (Ferrosan, Copenhagen, Denmark) soaked with dexamethasone $10 \mathrm{mg} / \mathrm{ml}$ was placed into the RWM for the time of implant bed drilling. The RWM was incised in the anterior part and lifted posteriorly with a short hook to open the anterior half of the round window. A hyaluronic acid-dexamethasone mixture (50:50 ratio) was then applied onto the RW area. Prior to loading the electrode, the hyaluronic acid-dexamethasone mixture was applied onto the array to ensure smooth gliding of the sheath during insertion. During insertion, special attention was paid to the appropriate orientation of the wing. The insertion and the removal of the sheath were performed as slowly as possible. The final position of the array was finally adjusted, with the distal marker inside the cochlea and the proximal marker outside. The white triangle was locked between the chorda-facial angle and was secured with bone paste and fibrin glue for stabilization. Finally, a tiny piece of temporal fascia was prepared and placed around the array to seal the RW.

On the first post-operative day, a cone-beam computed tomography (CBCT) was taken to assess the insertion results. The insertion depth angle (IDA) was measured and the scalar placement was evaluated (Fig. 1). All patients

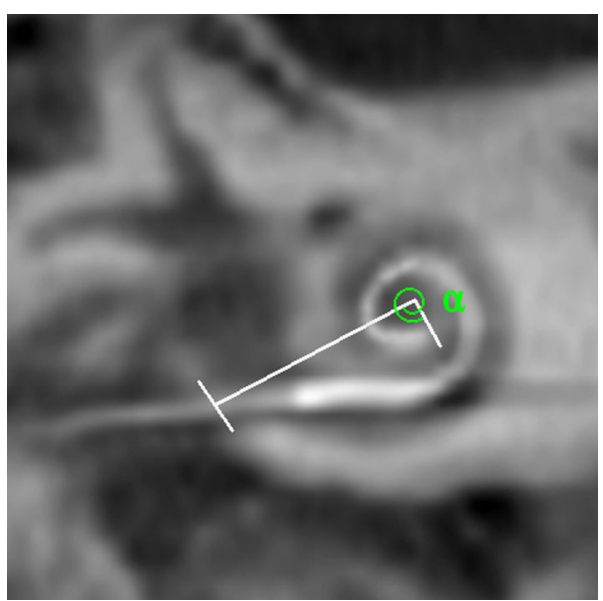

Fig. 1 Method for the insertion depth angle (IDA) measurement. Starting point for the first line is the level of RWM in middle of electrode, reaching to modiolus. Second line of the angle is drawn from modiolus to tip of electrode 
were discharged from the hospital on the first post-operative day. The patients did not receive any postoperative corticosteroid and/or antibiotic therapy.

The first postoperative hearing thresholds were mostly measured at the time of switch-on of the sound processor. Thresholds were measured routinely in the follow-up visits at approximately 6 and 12 months after activation.

The hearing preservation results are presented according to the following classifications used in the literature: The hearing thresholds were analyzed for PTA $(0.125-0.5 \mathrm{kHz})$, PTA $_{(0.125-1 \mathrm{kHz})}$ and for HEARRING classification $(S)$ $\left[S=1-\left(\frac{\text { PTApost-PTApre }}{\text { PTAmax-PTApre }}\right) * 100 \%\right]$ as described by Skarzynski et al. [30]. In the HEARRING classification, complete preservation was achieved whenever $S>75 \%$, partial $S=75-25 \%$ and loss when $<S 25 \%$. For PTA ${ }_{(0.125-0.5 \mathrm{kHz})}$ and PTA $(0.125-1 \mathrm{kHz})$, complete hearing preservation was achieved when the mean pre- and postoperative threshold deterioration was $\leq 15 \mathrm{~dB}$ (HL) and partial hearing preservation when the threshold shift was $\leq 30 \mathrm{~dB}$ (HL). A postoperative threshold deterioration $>30 \mathrm{~dB}$ (HL) was classified as minimal preservation.

Data were analyzed with Statistical Packages for the Social Sciences (SPSS) for Windows version 25 (SPSS Inc., Chigaco, IL, USA). Wilcoxon signed rank test was used in the statistical analysis when comparing hearing results. The Pearson test was used as a correlation test.

\section{Results}

All eighteen insertions could be performed through the RWM without any need to drill an extension. All insertions were carried out slowly, over $1 \mathrm{~min}$. There were no postoperative complications. In the post-operative CBCT, the mean IDA was 395 degrees (range $313^{\circ}-434^{\circ}$ ). All electrodes were fully inserted without any tip fold-over or scala translocations. The SME was located in close proximity to the modiolus in all but one ear. Information regarding the patient demographics and insertion results is summarized in Table 1. One patient with a psychiatric disorder (No. 13) insisted on the removal of the device after 3 months. Removal of cochlear implant was done 356 days after implantation. This patient has been excluded from end point results because data from a longer follow-up was not available.

The mean time between surgery and the first postoperative threshold measurements was 43 days (range 3-93, median 31). The mean follow-up time for all ears was 582 days (range 229-1041, median 482).
Table 1 Patient demographics and insertion results

\begin{tabular}{|c|c|c|c|c|c|c|c|}
\hline & Gender & Etiology & Age & Side & Approach & IDA & $\begin{array}{l}\text { Electrode } \\
\text { placement }\end{array}$ \\
\hline 1 & Male & Mb Meniere & 66 & Right & RW & 313 & ST \\
\hline 2 & Male & Usher Syndrome & 25 & Left & RW & 412 & ST \\
\hline 3 & Female & Mb Meniere & 41 & Right & RW & 405 & ST \\
\hline 4 & Male & SNHL & 11 & Right & RW & 406 & ST \\
\hline 5 & Male & SNHL & 17 & Right & RW & 396 & ST \\
\hline 6 & Female & SNHL & 22 & Right & RW & 424 & ST \\
\hline 7 & Female & Usher Syndrome & 11 & Right & RW & 390 & ST \\
\hline 8 & Female* & SNHL & 45 & Right & RW & 434 & ST \\
\hline 9 & Female* & SNHL & 45 & Left & RW & 410 & ST \\
\hline 10 & Female & Usher Syndrome & 31 & Right & RW & 423 & ST \\
\hline 11 & Male & Usher Syndrome & 28 & Right & RW & 392 & $\mathrm{ST}$ \\
\hline 12 & Female & SNHL & 52 & Left & RW & 390 & ST \\
\hline $13 * *$ & Male & Usher Syndrome & 49 & Right & RW & 400 & ST \\
\hline 14 & Male & SNHL & 67 & Right & RW & 400 & $\mathrm{ST}$ \\
\hline 15 & Female & SNHL & 65 & Right & RW & 380 & ST \\
\hline 16 & Female & SNHL & 71 & Left & RW & 360 & ST \\
\hline 17 & Male & SNHL & 52 & Right & RW & 377 & ST \\
\hline 18 & Male & SNHL & 24 & Right & RW & 391 & ST \\
\hline Mean & & & 40 & & & 395 & \\
\hline
\end{tabular}

$S N H L$ progressive sensorineural hearing loss of unknown origin, $R W$ round window, IDA insertion depth angle, $S T$ scala tympani

*Bilateral implantee; **Explantation after 356 days due to maladaptation 
There were no total hearing losses. Functional low frequency hearing PTA $\left._{(0.125-0.5 \mathrm{kHz})} \leq 80 \mathrm{~dB}(\mathrm{HL})\right)$ was preserved in 14 out of 17 ears $(82 \%)$. The mean postoperative deterioration in the PTA ${ }_{(0.125-0.5 \mathrm{kHz})}$ was $11 \mathrm{~dB}$ (HL). At end of the follow-up, complete hearing preservation was achieved in 14 out of 17 ears $(82.4 \%)$ for PTA $(0.125-0.5 \mathrm{kHz}$ and in 13 out of 17 ears $(76.5 \%)$, for PTA $(0.125-1 \mathrm{kHz})$. Partial preservation was achieved in $1 / 17(5.8 \%)$ and $3 / 17$ (17.6\%) and minimal preservation occurred in 2/17 (11.8\%) for PTA ${ }_{(0.125-0.5 \mathrm{kHz} \text { and in } 1 / 17(5.8 \%))}$ for PTA $(0.125-1 \mathrm{kHz})$. The corresponding rates for earlier threshold measurements at 3-93 days after surgery, showed a complete preservation rate in 15 out of 18 ears $(80.3 \%)$ for both PTA $(0.125-0.5 \mathrm{kHz})$ and PTA ${ }_{(0.125-1 \mathrm{kHz})}$. According to the HEARRING classification, 7 out of 17 ears $(41 \%)$ had complete hearing preservation and 10 out of 17 ears $(59 \%)$ had partial preservation at the end of follow-up. According to the earlier threshold measurements, complete hearing preservation was present in $55 \%$ of the ears and partial preservation in the remaining $45 \%$ when applying the HEARRING classification. The hearing preservation results according to the different classifications conducted in the early postoperative period and the final follow-up are summarized in Table $2 \mathrm{a}$ and $\mathrm{b}$. The overall hearing results are illustrated in Fig. 2.

We found a moderate correlation between the patient's age and the deterioration of the residual hearing at the final follow-up. The correlation coefficients were $r=0.603$ $(p=0.01)$ for PTA $_{(0.125-0.5 \mathrm{kHz})}$ and $r=0.613(p=0.009)$ for PTA $(0.125-1 \mathrm{kHz})$. There was no correlation between the baseline hearing and the preservation after surgery. For PTA $_{(0.125-0.5 \mathrm{kHz})}$, the correlation coefficient was $r=-0.341$ $(p=0.180)$; for PTA $(0.125-1 \mathrm{kHz})$ the value of $r$ was -0.417 $(p=0.096)$. We did not detect any significant differences between etiologies and the deterioration of residual hearing at the end of follow-up $\left(\mathrm{PTA}_{125-500 \mathrm{~Hz}} p=0.768\right.$ and for $\left.\mathrm{PTA}_{125-1000 \mathrm{~Hz}} p=0.649\right)$.

There were 14 ears (78\%) eligible for possible EAS and the vast majority, i.e. 13 ears $(72 \%)$ were primarily fitted with EAS. Subsequently, eight patients (nine ears) continued to use EAS. Two patients did not experience any subjective benefit from simultaneous acoustic stimulation and three patients preferred an open ear canal to the EAS strategy. The patient with bilateral SMEs used an EAS strategy in both of her ears.

The mean preoperative SRT was $-1.2 \mathrm{~dB}$ (SNR) (range -6.8 to $+10.0 \mathrm{~dB}(\mathrm{SNR}))$. The postoperative SRT improved significantly and was $-5.2 \mathrm{~dB}(\mathrm{SNR})$ (range -8.5 to $-0.7 \mathrm{~dB}(\mathrm{SNR}))$. The improvement of $\Delta-4.0 \mathrm{~dB}$ (SNR) with the Finnish matrix sentence was statistically significant $(p=0.01)$ and in the clinically expected magnitude. We found a significant (negative) correlation between IDA and post-operative speech test results $(r=-0.617 ; p=0.014)$, i.e. better post-operative speech test results with deeper IDA.
No correlations were detected for the pre- and postoperative SRT values $(r=0.251 ; p=0.367)$.

\section{Discussion}

The SME was originally developed to achieve less traumatic insertions through either the round window or via a cochleostomy. Our pre-clinical study revealed very consistent insertion results and one scala translocation out of twenty insertions in fresh frozen temporal bones [31]. Although the SME was not originally designed for hearing preservation, we observed good preservation of the residual hearing in our first clinical patients. Encouraged by these results, we started to use the SME also in patients with better hearing thresholds and ultimately even in patients eligible for EAS fitting. This study describes the SME's clinical results with an emphasis on hearing preservation in 17 consecutive patients (18 ears) with meaningful residual hearing.

Similar to the temporal bone study, the overall surgical handling was reasonably good. However, in patients with a narrow facial recess, the visibility to the round window may be obstructed by the bulky array-sheath assembly and in two cases, this compelled us to switch devices in favor of a slim LWE. Aschendorff et al. [32] also reported difficulties in the overall access to the round window area in some cases. Impaired visibility may easily lead to surgical inadequacies or even errors. Another surgical issue is that the inferior lip of the silicone sheath occasionally becomes stuck at the inferior border of the crista fenestra, complicating the introduction of the sheath into the cochlea. Upon loading of the array, the tip of the silicone sheath may open and spread which aggravates the aforementioned issue. Cuda and Murri [33] reported problems in two out of 61 insertions; in these two cases, several reloads and insertion attempts were required to achieve adequate insertion.

The insertion results with SME appear to be rather consistent. All insertions were performed through the RWM without any need for drilling an inferior extension. The mean IDA in our clinical series was $395^{\circ}$, which is almost identical to the IDA found in a temporal bone study and also similar to that reported in other studies [31, 32, 34]. Therefore, the cochlear coverage appears to be adequate for pure electrical stimulation.

Current publications have reported significantly higher rates of tip fold-over for the SME (4.5-7.7\%), compared to other LWE's (approx. 1\%) or stylet-type PME's (approx. 2-3\%) [32, 35-39]. McJunkin et al. [35] reported about 9 tip fold-overs out of 117 insertions (7.7\%), Gomes et al. [37] about two out 40 insertions (5\%) and Friedmann et al. [36] about 11 out of 237 insertions (4.6\%). In a multicenter 


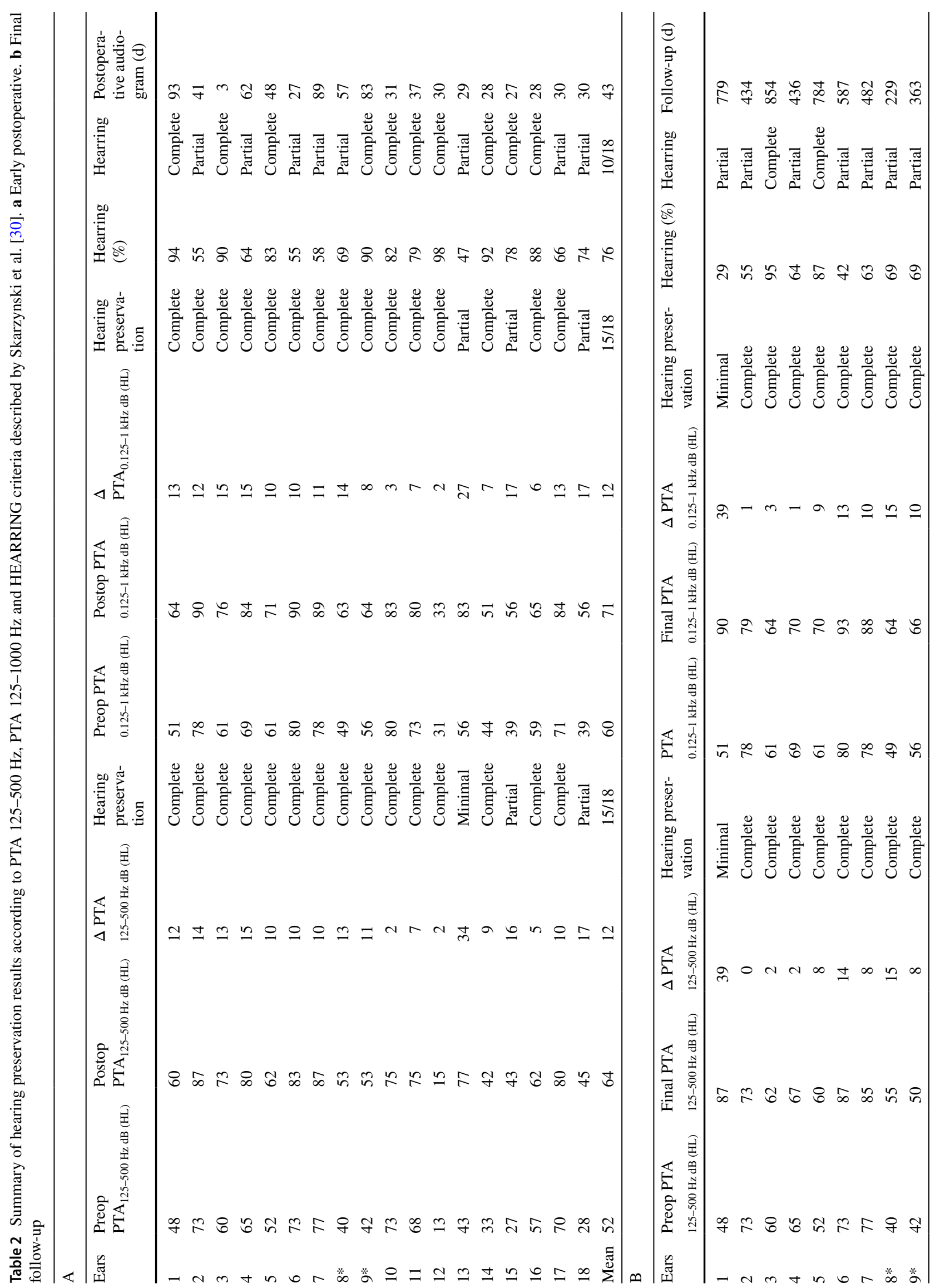




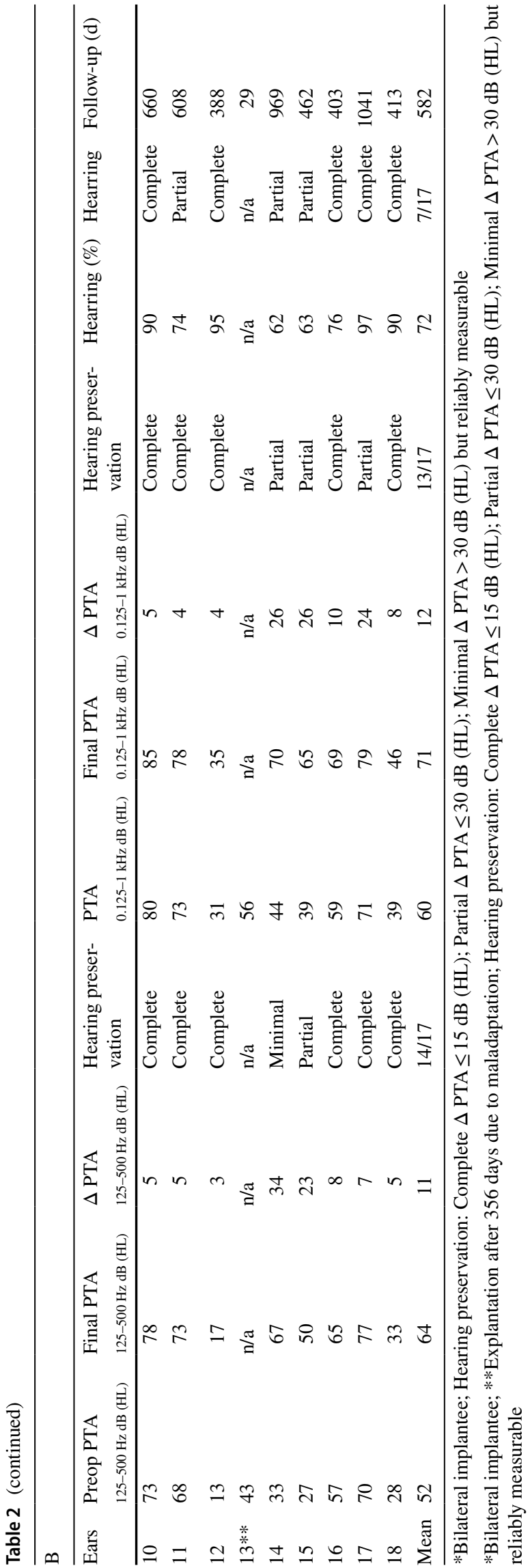

study, Aschendorff et al. [32] reported two tip fold-overs out of 44 insertions (4.5\%), which they attributed to surgical error. Unfortunately, they did not provide any detailed description of the specific error other than noting that the surgeon was not sufficiently experienced. Nevertheless, these reports demonstrate that postoperative imaging and/ or specific electrophysiological measurements are necessary to exclude tip fold-over with this array.

In our cohort of patients, we found no scala translocation on the CBCT images and all electrodes were in the scala tympani. McJunkin et al. [36] described scala translocation in 3 out of 23 insertions (13\%), whereas Aschendorff et al. [32] reported of no scala translocations. In summary, the translocation rates of the SME appear to be considerably lower than those reported for stylet-type PMEs, in the publications, their translocation rates have varied from $15.8 \%$ up to $52.3 \%$ [1, 2, 16, 22, 40, 41].

There are many different classifications for defining postoperative hearing preservation. We chose to present our data according to the most common definitions used in the literature. The hearing preservation rates achieved with the SME appear to be superior to other stylet-type PMEs [21, $42,43]$. The majority of patients $(72 \%)$ were initially fitted with an EAS strategy and $44 \%$ experienced benefits with the acoustic stimulation and continued to use the device. Roland et al. [11] reported on 50 patients eligible for EAS who were implanted with short $16 \mathrm{~mm}$ LWE; of these, 33 (66\%) were postoperatively fitted with an EAS processor and 23 patients were still benefiting from EAS 5 years after surgery [44]. Although the overall hearing preservation results of the SME appear to be inferior to those reported for a shorter $16 \mathrm{~mm} \mathrm{LWE}$, the SME has the clear advantage of providing adequate cochlear coverage for pure electric stimulation should the residual hearing deteriorate. Therefore, it eliminates the possible need for re-implantation with a longer electrode. Roland et al. [11] reported the need for five revision surgeries out of 50 EAS patients (10\%) in which the $16 \mathrm{~mm}$ LWE had to be replaced with a longer array to provide adequate hearing performance with electric stimulation. In our study, the mean postoperative threshold deterioration for PTA $(0.125-1 \mathrm{kHz})$ was $12 \mathrm{~dB}(\mathrm{HL})$, which is comparable to the value reported by Gantz et al. [7], who found a mean threshold decline of $9 \mathrm{~dB}(\mathrm{HL})$ with a $16 \mathrm{~mm}$ LWE. Ramos et al. [43] compared the hearing preservation results of the SME with a $20 \mathrm{~mm}$ slim LWE and stylet-type PME. The hearing preservation $\left(\mathrm{PTA}_{(0.125-0.750 \mathrm{kHz})}<15 \mathrm{~dB}\right.$ (HL)) results with the SME (50\%) and the slim LWE (43\%) were similar to our series, whereas very poor hearing preservation $(0 \%)$ was encountered with the stylet-type PMEs.

When comparing the results according to the HEARRING classification, complete preservation was observed in $47 \%$ of ears. In pediatric patients, Manjaly et al. [45] reported complete hearing preservation in $55 \%$ for $20 \mathrm{~mm}$ 

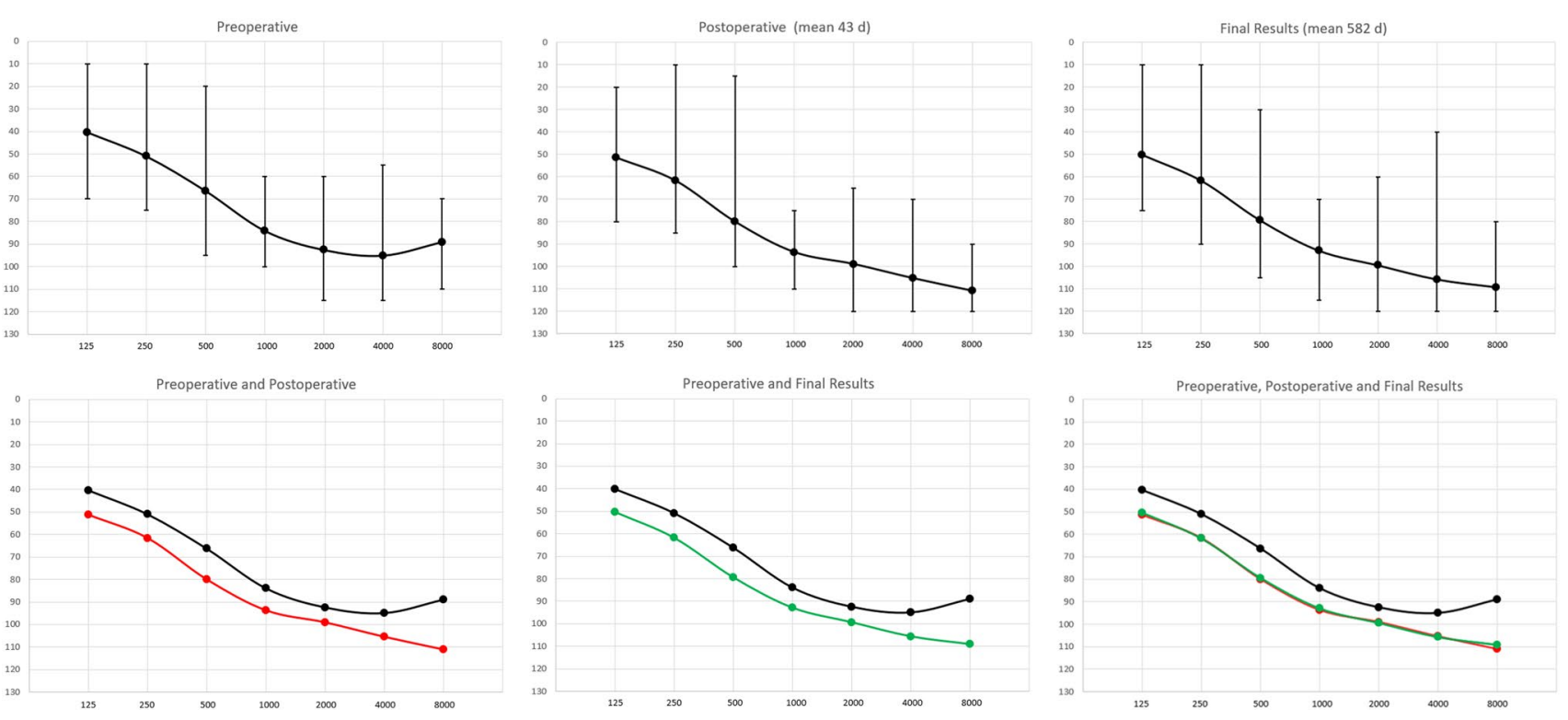

Fig. 2 Mean hearing thresholds with minimum and maximum. a) preoperative b) early postoperative c) final follow-up

and $28 \mathrm{~mm}$ LWEs. There is another report of complete hearing preservation in nine out 25 patients (35\%) with LWEs of different lengths after 1 year [46].

LWEs are reported to achieve low frequency hearing preservation in a wide range from 11.3 to $77.7 \%[14,17,18$, 20]. Our results were $82.4 \%$ for PTA ${ }_{(0.125-0.5 \mathrm{kHz})}$ and $76.5 \%$ for PTA $(0.125-1 \mathrm{kHz})$. Although there is some variation in the methods of assessing low-frequency preservation between different studies, we have achieved comparable short-term preservation results with the SME as reported for LWE. We were not able to measure the thresholds immediately after surgery, which raises the question of whether the threshold shift was due to direct insertion trauma or to postoperative inflammation.

We found an age-related effect on the postoperative hearing preservation. Zanetti et al. [47] reported better hearing preservation rates with children as compared to adults, but this difference was not statistically significant. In the systematic review conducted by Causon et al. [48], age was not a significant factor for hearing preservation. Thus, it is uncertain whether age is a contributing factor behind hearing preservation. We found no correlation between the baseline residual hearing with the preservation rates.

We found a significant improvement in the speech recognition in noise as measured with the FMST. The mean improvement of the speech reception threshold in noise after implantation of $4.0 \mathrm{~dB}$ (SRN) was clinically most significant and in the range of the desired and expected improvement [29]. One interesting finding was that the postoperative SRT correlated significantly with the insertion depth (i.e. the deeper the insertion, the better the postoperative SRT).
There is published data which has revealed a correlation between deeper insertion angles with better postoperative hearing outcomes $[4,15,40]$. This correlation is all the more surprising, since in our series there were seven patients (eight ears) with EAS for whom the IDA is not considered to be critical. However, caution is necessary in the interpretation of this correlation due to the small number of patients.

The limitations of this study are inherent in its retrospective nature. The statistical power of the analysis is weakened by the small size and heterogeneity of the cohort. Additionally, our finding should be regarded as preliminary, since a longer follow-up will be needed to evaluate the long-term hearing preservation results.

\section{Conclusion}

The hearing preservation results with the SME were superior to those reported for stylet type PMEs. In several cases, residual hearing was well preserved which enabled patients to use EAS stimulation. Although the hearing preservation rate of the SME was inferior to that achieved with short LWEs, it provided deeper insertions and better cochlear coverage for pure electrical stimulation in the event of postoperative or progressive hearing loss. This may have obviated the need for re-implantation with a longer electrode in the event of postoperative or progressive hearing loss.

Acknowledgements Open access funding provided by University of Eastern Finland (UEF) including Kuopio University Hospital. 
Funding Kuopio University Hospital (VTR), the Finnish Academy and the Pohjois-Savon maakuntarahasto has provide funding for the Kuopio Cochlear Implant Research group to conduct this study.

\section{Compliance with ethical standards}

Conflict of interest The authors report of no conflicts of interests.

Ethical approval The study had institutional approval (No. 5551850).

Informed consent This was retrospective study, thus no informed consent was needed.

Open Access This article is distributed under the terms of the Creative Commons Attribution 4.0 International License (http://creativeco mmons.org/licenses/by/4.0/), which permits unrestricted use, distribution, and reproduction in any medium, provided you give appropriate credit to the original author(s) and the source, provide a link to the Creative Commons license, and indicate if changes were made.

\section{References}

1. Aschendorff A, Kromeier J, Klenzner T, Laszig R (2007) Quality control after insertion of the nucleus contour and contour advance electrode in adults. Ear Hear 28(2 Suppl):75S-79S

2. Finley CC, Holden TA, Holden LK et al (2008) Role of electrode placement as a contributor to variability in cochlear implant outcomes. Otol Neurotol 29(7):920-928. https://doi.org/10.1097/ MAO.0b013e318184f492

3. Holden LK, Finley CC, Firszt JB et al (2013) Factors affecting open-set word recognition in adults with cochlear implants. Ear Hear 34(3):342-360. https://doi.org/10.1097/AUD.0b013e3182 $741 \mathrm{aa} 7$

4. O'Connell BP, Cakir A, Hunter JB et al (2016) Electrode location and angular insertion depth are predictors of audiologic outcomes in cochlear implantation. Otol Neurotol 37(8):1016-1023. https:// doi.org/10.1097/MAO.0000000000001125

5. Carlson ML, Driscoll CLW, Gifford RH et al (2011) Implications of minimizing trauma during conventional cochlear implantation. Otol Neurotol 32(6):962-968. https://doi.org/10.1097/ MAO.0b013e3182204526

6. von Ilberg C, Kiefer J, Tillein J, Pfenningdorff T, Hartmann R, Stürzebecher E, Klinke R (1999) Electric-acoustic stimulation of the auditory system. New technology for severe hearing loss. ORL J Otorhinolaryngol Relat Spec 61(6):334-340

7. Gantz BJ, Turner CW (2003) Combining acoustic and electrical hearing. Laryngoscope 113(10):1726-1730

8. Gantz BJ, Turner C, Gfeller KE, Lowder MW (2005) Preservation of hearing in cochlear implant surgery: advantages of combined electrical and acoustical speech processing. Laryngoscope 115(5):796-802

9. Gifford RH, Dorman MF, Skarzynski H et al (2013) Cochlear implantation with hearing preservation yields significant benefit for speech recognition in complex listening environments. Ear Hear 34(4):413-425. https://doi.org/10.1097/AUD.0b013e3182 $7 \mathrm{e} 8163$

10. Lenarz T, James C, Cuda D et al (2013) European multi-centre study of the Nucleus Hybrid L24 cochlear implant. Int J Audiol 52(12):838-848. https://doi.org/10.3109/14992027.2013.802032 (Epub 2013 Sep 2)

11. Roland JT, Gantz BJ, Waltzman SB, Parkinson AJ, Multicenter Clinical Trial Group (2016) United States multicenter clinical trial of the cochlear nucleus hybrid implant system. Laryngoscope 126(1):175-181. https://doi.org/10.1002/lary.25451

12. Nguyen Y, Mosnier I, Borel S et al (2013) Evolution of electrode array diameter for hearing preservation in cochlear implantation. Acta Otolaryngol 133(2):116-122. https://doi.org/10.3109/00016 489.2012.723824

13. Suhling M, Majdani O, Salcher R, Leifholz M, Büchner A, Lesinski-Schiedat A, Lenarz T (2016) The impact of electrode array length on hearing preservation in cochlear implantation. Otol Neurotol 37(8):1006-1015. https://doi.org/10.1097/MAO.00000 00000001110

14. Jurawitz M, Büchner A, Harpel T, Schüssler M, Majdani O, Lesinski-Schiedat A, Lenarz T (2014) Hearing preservation outcomes with different cochlear implant electrodes: nucleus ${ }^{\circledR}$ Hybrid $^{\text {TM }}-$ L24 and Nucleus Freedom ${ }^{\mathrm{TM}}$ CI422. Audiol Neurootol 19(5):293-309. https://doi.org/10.1159/000360601

15. Buchman CA, Dillon MT, King ER, Adunka MC, Adunka OF, Pillsbury HC (2014) Influence of cochlear implant insertion depth on performance: a prospective randomized trial. Otol Neurotol 35(10):1773-1779. https://doi.org/10.1097/ MAO.0000000000000541

16. Wanna GB, Noble JH, Gifford RH et al (2015) Impact of intrascalar electrode location, electrode type, and angular insertion depth on residual hearing in cochlear implant patients: preliminary results. Otol Neurotol 36(8):1343-1348. https://doi. org/10.1097/MAO.0000000000000829

17. Helbig S, Helbig M, Leinung M, Stöver T, Baumann U, Rader $\mathrm{T}$ (2015) Hearing preservation and improved speech perception with a flexible 28-mm electrode. Otol Neurotol 36(1):34-42. https://doi.org/10.1097/MAO.0000000000000614

18. Helbig S, Adel Y, Rader T, Stöver T, Baumann U (2016) Longterm hearing preservation outcomes after cochlear implantation for electric-acoustic stimulation. Otol Neurotol 32(6):973-979. https://doi.org/10.1097/MAO.0b013e31822558c4

19. Skarzynski H, Matusiak M, Furmanek M, Pilka A, Wlodarczyk E, Oldak M, Skarzynski PH (2018) Radiologic measurement of cochlea and hearing preservation rate using slim straight electrode (CI422) and round window approach. Acta Otorhinolaryngol Ital 38(5):468-475. https://doi.org/10.14639 /0392-100X-1579

20. Helbig S, Baumann U, Hey C, Helbig M (2011) Hearing preservation after complete cochlear coverage in cochlear implantation with the free-fitting FLEXSOFT electrode carrier. Otol Neurotol 32(6):973-979. https://doi.org/10.1097/MAO.0b013e31822558c 4

21. Fraysse B, Macías AR, Sterkers O et al (2006) Residual hearing conservation and electroacoustic stimulation with the nucleus 24 contour advance cochlear implant. Otol Neurotol 27(5):624-633

22. O'Connell BP, Hunter JB, Wanna GB (2016) The importance of electrode location in cochlear implantation. Laryngoscope Investig Otolaryngol 1(6):169-174. https://doi.org/10.1002/lio2.42

23. Souter MA, Briggs RJS, Wright CG, Roland PS (2011) Round window insertion of precurved perimodiolar electrode arrays: how successful is it? Otol Neurotol 32(1):58-63. https://doi. org/10.1097/MAO.0b013e3182009f52

24. Cohen LT, Saunders E, Knight MR, Cowan RSC (2006) Psychophysical measures in patients fitted with contour and straight nucleus electrode arrays. Hear Res 212(1-2):160-175

25. Long CJ, Holden TA, McClelland GH, Parkinson WS, Shelton C, Kelsall DC, Smith ZM (2014) Examining the electro-neural interface of cochlear implant users using psychophysics, CT scans, and speech understanding. J Assoc Res Otolaryngol 15(2):293-304. https://doi.org/10.1007/s10162-013-0437-5

26. Marrinan MS, Roland JT, Reitzen SD, Waltzman SB, Cohen LT, Cohen NL (2004) Degree of modiolar coiling, electrical 
thresholds, and speech perception after cochlear implantation. Otol Neurotol 25(3):290-294

27. Adunka OF, Gantz BJ, Dunn C, Gurgel RK, Buchman CA (2018) Minimum reporting standards for adult cochlear implantation. Otolaryngol Head Neck Surg 159(2):215-219. https://doi. org/10.1177/0194599818764329

28. Dietz A, Buschermöhle M, Aarnisalo AA et al (2014) The development and evaluation of the Finnish Matrix Sentence Test for speech intelligibility assessment. Acta Otolaryngol 134(7):728737. https://doi.org/10.3109/00016489.2014.898185

29. Dietz A, Buschermöhle M, Sivonen V, Willberg T, Aarnisalo AA, Lenarz T, Kollmeier B (2015) Characteristics and international comparability of the Finnish matrix sentence test in cochlear implant recipients. Int J Audiol 54(Suppl 2):80-87. https://doi. org/10.3109/14992027.2015.1070309

30. Skarzynski H, van de Heyning P, Agrawal S et al (2013) Towards a consensus on a hearing preservation classification system. Acta Otolaryngol Suppl 1(564):3-13. https://doi.org/10.3109/00016 489.2013.869059

31. Iso-Mustajärvi M, Matikka H, Risi F et al (2017) a new slim modiolar electrode array for cochlear implantation: a radiological and histological study. Otol Neurotol 38(9):e327-e334. https:// doi.org/10.1097/MAO.0000000000001542

32. Aschendorff A, Briggs R, Brademann G et al (2017) Clinical investigation of the Nucleus Slim Modiolar Electrode. Audiol Neurootol 22(3):169-179. https://doi.org/10.1159/000480345

33. Cuda D, Murri A (2017) Cochlear implantation with the nucleus slim modiolar electrode (CI532): a preliminary experience. Eur Arch Otorhinolaryngol 274(12):4141-4148. https://doi. org/10.1007/s00405-017-4774-6

34. Briggs RJS, Tykocinski M, Lazsig R et al (2011) Development and evaluation of the modiolar research array-multi-centre collaborative study in human temporal bones. Cochlear Implants Int 12(3):129-139. https://doi.org/10.1179/1754762811Y000000000 7

35. McJunkin JL, Durakovic N, Herzog J, Buchman CA (2018) Early outcomes with a slim, modiolar cochlear implant electrode array. Otol Neurotol 39(1):e28-e33. https://doi.org/10.1097/ MAO.0000000000001652

36. Friedmann DR, Kamen E, Choudhury B, Roland JT (2019) Surgical experience and early outcomes with a slim perimodiolar electrode. Otol Neurotol 40(3):e304-e310. https://doi.org/10.1097/ MAO.0000000000002129

37. Gomez Serrano M, Patel S, Harris R, Selvadurai D (2019) Initial surgical and clinical experience with the nucleus CI532 slim modiolar electrode in the UK. Cochlear Implants Int 20(4):207216. https://doi.org/10.1080/14670100.2019.1597461

38. Cosetti MK, Troob SH, Latzman JM, Shapiro WH, Roland JT, Waltzman SB (2012) An evidence-based algorithm for intraoperative monitoring during cochlear implantation. Otol Neurotol 33(2):169-176. https://doi.org/10.1097/MAO.0b013 e3182423175

39. Zuniga MG, Rivas A, Hedley-Williams A et al (2017) Tip fold-over in cochlear implantation: case series. Otol Neurotol 38(2):199-206. https://doi.org/10.1097/MAO.0000000000001283

40. Wanna GB, Noble JH, Carlson ML et al (2014) Impact of electrode design and surgical approach on scalar location and cochlear implant outcomes. Laryngoscope 124(Suppl 6):S1-S7. https://doi. org/10.1002/lary. 24728

41. Sipari S, Iso-Mustajärvi M, Löppönen H, Dietz A (2018) The insertion results of a mid-scala electrode assessed by mri and cbct image fusion. Otol Neurotol 39(10):e1019-e1025. https:// doi.org/10.1097/MAO.0000000000002045

42. Benghalem A, Gazibegovic D, Saadi F, Tazi-Chaoui Z (2017) Use of a mid-scala and a lateral wall electrode in children: insertion depth and hearing preservation. Acta Otolaryngol 137(1):1-7

43. Ramos-Macías A, Borkoski-Barreiro SA, Falcón-González JC, Ramos-de Miguel A (2017) Hearing preservation with the slim modiolar electrode nucleus ci532 ${ }^{\circledR}$ cochlear implant: a preliminary experience. Audiol Neurootol 22(6):317-325. https://doi. org/10.1159/000486409

44. Roland JT, Gantz BJ, Waltzman SB, Parkinson AJ (2018) Longterm outcomes of cochlear implantation in patients with highfrequency hearing loss. Laryngoscope 128(8):1939-1945. https ://doi.org/10.1002/lary.27073

45. Manjaly JG, Nash R, Ellis W et al (2018) Hearing preservation with standard length electrodes in pediatric cochlear implantation. Otol Neurotol 39(9):1109-1114. https://doi.org/10.1097/ MAO.0000000000001917

46. Sierra C, Calderón M, Bárcena E, Tisaire A, Raboso E (2019) Preservation of residual hearing after cochlear implant surgery with deep insertion electrode arrays. Otol Neurotol 40(4):e373e380. https://doi.org/10.1097/MAO.0000000000002170

47. Zanetti D, Nassif N, Redaelli de Zinis LO (2015) Factors affecting residual hearing preservation in cochlear implantation. Acta otorhinolaryngologica Italica 35(6):433-441. https://doi. org/10.14639/0392-100X-619

48. Causon A, Verschuur C, Newman T (2015) A retrospective analysis of the contribution of reported factors in cochlear implantation on hearing preservation outcomes. Otol Neurotol 36(7):11371145. https://doi.org/10.1097/MAO.0000000000000753

Publisher's Note Springer Nature remains neutral with regard to jurisdictional claims in published maps and institutional affiliations. 